\title{
Instrumento de inteligência turística e tomada de decisão: o caso do Observatório do Turismo do Maranhão
}

\author{
Instrument of tourist intelligence and decision making: the case of the Tourism \\ Observatory of Maranhão
}

\section{Instrumento de inteligencia turística y toma de decisión: el caso del Observatorio del Turismo de Maranhão}

\section{Saulo Ribeiro dos Santos ${ }^{1}$ Thais Mendes Pinheiro²}

\begin{abstract}
Resumo: Em se tratando de dados estatísticos no turismo para fins de tomada de decisão e elaboração de políticas públicas, estes são decisivos para que os destinos turísticos tenham condições de ofertar novos produtos e serviços, preparando-se para atender às reais necessidades de seus visitantes. Desta forma, objetiva-se neste presente estudo relatar as experiências de trabalho do Observatório do Turismo do Maranhão como instrumento de inteligência e tomada de decisão para a elaboração de políticas públicas de turismo no estado do Maranhão. Utilizou-se de pesquisa bibliográfica e documental, e caracteriza-se como descritiva e exploratória, além do relato de experiência dos membros sobre o funcionamento e dinâmica do Observatório. Conclui-se que a criação do Observatório do Turismo do Maranhão no ano de 2017 tem criado dados até então inexistentes e atualizado outros, de forma a contribuir para o fortalecimento dos polos turísticos do Maranhão.
\end{abstract}

Palavras chave: Dados estatísticos; Observatório do turismo do Maranhão; Políticas públicas; Tomada de decisão.

Summary: Dealing with statistical in tourism for the purposes of decision-making and public policy-making, are decisive for tourist destinations to be able to offer new products and services, and also preparing themselves to meet the real needs of their visitors. In this way, this study aims to report the work experiences of the Tourism Observatory of Maranhão as an instrument of intelligence and decision-making for the elaboration of public tourism policies in the state of Maranhão. Bibliographical and documentary research was used, and it is characterized as descriptive and exploratory, in addition to the report of experience of the members on the operation and dynamics of the Observatory. It is concluded that the creation of the Tourism Observatory of Maranhão in the year 2017 has created data previously non existent and updated others, in order to contribute to the strengthening of the tourist centers of Maranhão.

\footnotetext{
${ }^{1}$ Bacharel em Turismo, Mestre em Administração e Desenvolvimento Empresarial, Doutor em Gestão Urbana, Doutor em Geografia. Professor do Departamento de Turismo e Hotelaria da Universidade Federal do Maranhão e do Programa de Mestrado em Geografia, Natureza e Dinâmica do Espaço na Universidade Estadual do Maranhão. Coordenador do Observatório do Turismo do Maranhão. E-mail: saulosantosma@uol.com.br ORCID: https://orcid.org/0000-0002-6596-0016

${ }^{2}$ Bacharel em Turismo e Administração. Supervisora de Serviços Turísticos da Secretaria de Turismo do Maranhão. Vice Coordenadora do Observatório do Turismo do Maranhão. E-mail: thays.pinheiro@gmail.com

Financiamento: O Observatório do Turismo do Maranhão é financiado pela Universidade Federal do Maranhão, Secretaria de Estado de Turismo do Maranhão, Secretaria Municipal de Turismo de São Luís e Serviço Brasileiro de Apoio a Micro e Pequenas Empresas do Maranhão.
} 
Keywords: Statistical; Tourism Observatory of Maranhão; Public policy; Decision making.

Resumen: En sí tratando de datos estadísticos en el turismo para fines de toma de decisión y elaboración de políticas públicas, estos son decisivos para que los destinos turísticos tengan condiciones de ofrecer nuevos productos y servicios, preparándose para atender a las reales necesidades de sus visitantes. De esta forma, se objetiva en este presente estudio relatar las experiencias de trabajo del Observatorio del Turismo de Maranhão como instrumento de inteligencia y toma de decisión para la elaboración de políticas públicas de turismo en el estado de Maranhão. Se utilizó de investigación bibliográfica y documental, y se caracteriza como descriptiva y exploratoria, además del relato de experiencia de los miembros sobre el funcionamiento y dinámica del Observatorio. Se concluye que la creación del Observatorio del Turismo de Maranhão en el año 2017 ha creado datos hasta entonces inexistentes y actualizados otros, de forma a contribuir con el fortalecimiento de los polos turísticos de Maranhão.

Palabras clave: Datos estadísticos; Observatorio del turismo de Maranhão; Políticas públicas; Toma de decisiones.

\section{Introdução}

É imprescindível entender e perceber a realidade turística de um determinado destino turístico (Butler, 2008; Framke, 2002), pois, deve-se levar em consideração que no território turístico acontece o desenvolvimento da atividade turística, e, portanto, é necessária sua compreensão (Santos, 2016). Além disso, o fenômeno turístico por sua complexidade sistêmica deve estar aliado a um modelo de planejamento turístico (Santos, 2016) que oriente a uma tomada de decisão inteligente em qualquer âmbito de desenvolvimento, pois, este requer a existência de dados e indicadores de natureza estatística conforme destacam Luque Gil \& Zayas Fernández \& Caro Herrero (2015).

É assim que municípios, estados e países em todo o mundo vem realizando, mediante instituições e mecanismos que elaboram tais informações, pois, estas são vitais para a elaboração de políticas e planos estratégicos (Blasco Franch \& Cuevas Contreras, 2013; Luque Gil \& Zayas Fernández \& Caro Herrero, 2015). Para cada área temática, o estado busca obter dados significativos e relevantes. Em geral, tem-se um conjunto de informações sobre economia, saúde, educação, entre outros, e o turismo é uma área recente, que carece de dados e que está diretamente relacionada à economia (Marco Lajara \& García Lillo \& Sabater Sempere, 2009).

Quanto ao turismo, Blasco Franch \& Cuevas Conteras (2013) afirmam que gestores de destinos turísticos devem se preocupar em obter informações adequadas para acompanhar e avaliar o desenvolvimento da atividade, e, que diversos destinos (maduros ou não) ainda não possuem observatório. Autores como Luque Gil \& Zayas Fernández \& Caro Herrero (2015) ressaltam a notoriedade de que há uma convergência mundial sobre a busca por dados relativos quanto ao turismo, pois, não é prioritário em diversos países e são difíceis de conseguir, como o caso do Brasil (Mtur, 2018). Além disso, compreende-se que o 
turismo é uma atividade que gera impactos ambientais, culturais, econômicos e sociais numa localidade, e, é imprescindível criar uma instância que disponha de informações precisas e de qualidade para apoiar na tomada de decisão estratégica, com fins de desenvolvimento turístico (Blasco Franch \& Cuevas Contreras, 2013).

Assim, os observatórios de turismo têm papel relevante na obtenção de dados, pois, para Luque Gil \& Zayas Fernández \& Caro Herrero (2015) e Unwto (2017) o conceito de Observatório de Turismo é uma ferramenta de inteligência turística estável, responsável por observar a realidade, além de analisar a dinâmica territorial, utilizando softwares para medir os dados, retornando-os em forma de tabelas, gráficos, mapas e indicadores estatísticos, fornecendo resultados a todos os stakeholders do destino turístico.

Tanto no Brasil, quanto no estado do Maranhão as estatísticas sobre o turismo são escassas, com pouco detalhamento e até mesmo desarticuladas com outros setores, e nem se compara a abundância de dados de outros segmentos (Mtur, 2018; Maranhão, 2012). Inclusive, no atual Plano Nacional de Turismo (2018-2022) uma das iniciativas é apoiar a estruturação de uma rede Observatórios de Turismo no Brasil, pois:

\begin{abstract}
Um observatório de turismo tem entre os seus objetivos o acompanhamento, observação, coleta, tratamento, análise, geração e monitoramento de dados e informações sistemáticas e padronizadas sobre atividade turística em distintos níveis administrativos regional, estadual e municipal. Trata-se de um recurso institucional que permite acompanhar o desempenho do turismo em determinado nível administrativo, contribuindo para o planejamento sustentável da atividade e para fortalecer o turismo como opção de desenvolvimento econômico (Mtur, 2018, p. 83).
\end{abstract}

A partir desta ótica, compreende-se a necessidade do desenvolvimento de Observatórios de Turismo no Brasil com o objetivo de disseminar dados e informações para que a cadeia produtiva do turismo tenha acesso e possa tomar decisão de forma inteligente como acontece na Espanha, por exemplo (Agencia Aysén, 2009).

No estado do Maranhão (Nordeste, Brasil) o turismo vem sendo desenvolvido como política pública "permanente" a partir da implementação do documento Plano Estratégico de Turismo do Estado do Maranhão (Plano Maior) desde o ano 2000, onde foram criados metas, diretrizes, objetivos, entre outros, além da definição de polos turísticos que direcionaram ações específicas de fortalecimento da atividade. Desde a criação do Plano Maior, o Maranhão passou de 05 (cinco) para 10 (dez) polos turísticos categorizados em Indutores, Estratégicos e Desenvolvimento, os quais possuem diferentes condições de desenvolvimento do turismo, assim relacionados às suas atratividades, formas de organização e gestão, contextos sociais e econômicos, entre outros (Maranhão, 2012).

Neste documento norteador há inúmeras justificativas sobre dados estatísticos sequenciais do turismo no Maranhão, que levam o estado a "amparar-se" em dados regionais ou nacionais, o que não acompanha a realidade local, conforme observa-se: "as 
estatísticas disponíveis atualmente são inadequadas e insuficientes para dimensionar os fluxos turísticos no Maranhão e nos polos e/ou para acompanhar sua evolução nos últimos anos" (Maranhão, 2012, p. 14).

Mediante tais aspectos, objetiva-se no presente estudo relatar as experiências de trabalho do Observatório do Turismo do Maranhão como instrumento de inteligência e tomada de decisão para a elaboração de políticas públicas de turismo no estado do Maranhão.

O artigo está subdividido em quatro tópicos, sendo inicialmente a introdução com uma breve justificativa e o objetivo, seguido da metodologia com os métodos e técnicas utilizados, posteriormente a análise dos dados, e por fim, as considerações finais.

\section{Procedimentos metodológicos}

Os procedimentos metodológicos adotados foram a webresearch (Gil, 2006) mediante buscas na base de dados Redalyc, num recorte temporal dos artigos publicados a partir de 2005 utilizando palavras chaves como "observatório do turismo" e "dados estatísticos e turismo", e documental, especificamente no Plano Maior ${ }^{3}$ e na Política Nacional de Turismo (2018-2022). A pesquisa tem caráter exploratório-descritivo (Vergara, 2004), pois, busca-se apresentar um referencial teórico em que se compreenda e amplie as perspectivas e discussão sobre observatórios de turismo.

Trata-se também de um estudo de caso (Yin, 2001) de um organismo específico (unidade única de análise). Optou-se pelo relato de experiências dos participantes do Observatório com a finalidade de apresentar as vivências dos mesmos durante as pesquisas desenvolvidas pelo Observatório, evidenciando as respostas registradas e coletadas em diversas reuniões pós pesquisa.

Assim, transcreveu-se as percepções, pois, considera-se tais conteúdos fundamentais para revelar a importância do Observatório do Turismo do Maranhão para o desenvolvimento de políticas públicas e tomada de decisão. Os resultados foram elaborados a partir de uma construção individual e coletiva das experiências de trinta dos mais de cem pesquisadores (fixos e não fixos) desde 2017 a 2019 sobre as ações executadas pelo Observatório do Turismo do Maranhão, como as pesquisas de demandas realizadas e sua importância para as políticas e planos turísticos, num formato de um texto descritivo e analítico, que serve de base para responder o objetivo do artigo (Todorov, 1979).

\footnotetext{
${ }^{3}$ Plano Estratégico de Turismo do Estado do Maranhão.
} 


\section{Resultados e análise}

O Observatório do Turismo do Maranhão surge a partir da premissa da insuficiência de dados estatísticos permanentes e contínuos sobre o turismo no estado do Maranhão (Maranhão, 2012). A partir desta prerrogativa, o grupo de pesquisa "Turismo, Cidades e Patrimônio" da Universidade Federal do Maranhão elabora o projeto do Observatório para que pudesse servir como instância de gestão de conhecimento científico para subsidiar as políticas públicas e auxiliar na tomada de decisão inteligente tanto para o setor público quanto privado (Observatório do Turismo do Maranhão, 2017).

Mediante tais abordagens, o Grupo de Pesquisa justificou a importância do Observatório do Turismo do Maranhão, pois, este já era previsto no Plano Maior 2020 (Programa Tecnologia do Turismo, subitem Rede de Conhecimento) para o ano de 2014 (Maranhão, 2012). Sendo assim, os objetivos específicos do Observatório do Turismo do Maranhão são: a) obter, sistematizar, processar, analisar e difundir informação de qualidade e confiável sobre a atividade turística do estado do Maranhão; b) obter e processar informações quantitativas e qualitativas sobre a oferta e demanda turística do Maranhão; c) desenvolver estudos e pesquisas de caráter quantitativo e qualitativo de interesse para o desenvolvimento turístico do Maranhão; d) consolidar e sistematizar informação de interesse turístico para diversas instituições e organismos públicos e privados do Maranhão; e) aproximar instituições, empresas e pesquisadores que tenham interesse pelas pesquisas propostas pelo Observatório; f) estimular a criação de uma rede de informações no estado do Maranhão; g) estruturar um website que deve ser periodicamente atualizado atendendo o fornecimento de dados a prefeituras, trade, instituições de ensino, organizações civis em comunidade em geral; h) utilizar as informações e dados das pesquisas no planejamento de ações e estratégias da política de turismo do Estado; i) promover a produção e divulgação de dados e informações que contribuam para o turismo na área de abrangência do observatório e que tenham aplicabilidade prática.

Quanto ao organograma (composto por coordenador e vice coordenador; comitê executivo; secretário(a) executivo(a), e; pesquisadores permanentes e voluntários), este segue uma estrutura sólida e enxuta, adequada aos atuais parâmetros da gestão de pessoas. Além de organizar as funções de cada colaborador do Observatório, criaram a marca (Figura 1), pois, esta acrescenta valor ao produto, valorizando-o e identificando-o perante seus pares. Portanto, a sua concepção está baseada em princípios básicos de pesquisa, fazendo-se necessária para que o Observatório do Turismo do Maranhão tenha a sua representação, mantendo-o competitivo e permanente no mercado (Observatório do Turismo do Maranhão, 2017). 


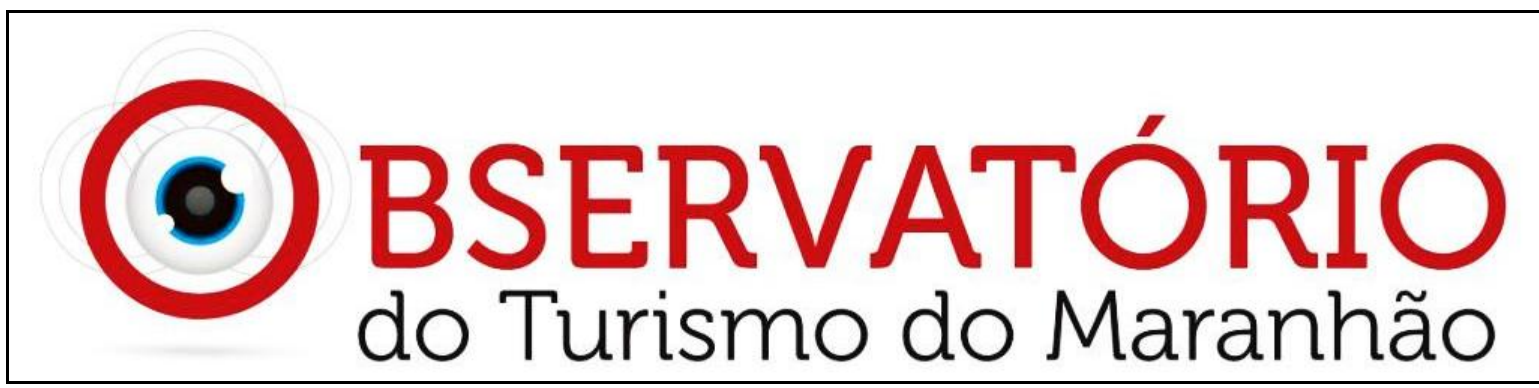

Figura 1: Marca oficial do Observatório do Turismo do Maranhão

Fonte: Observatório do Turismo do Maranhão (2017)

Além disso, é uma garantia de origem e qualidade para aquele que a identifica (AAKER, 2007). Quanto aos eixos de pesquisa do Observatório, este está dividido em três: a) Documental; b) Campo; c) Mineração de dados. Em relação aos pesquisadores fixos e não fixos, estes são estudantes dos cursos de Turismo e Hotelaria vinculados à Universidade Federal do Maranhão e/ou outra Instituição de Educação Pública ou Privada, os quais foram previamente treinados e orientados quanto à aplicação de questionários e abordagem ao turista.

A partir da institucionalização do Observatório do Turismo do Maranhão pela Universidade Federal do Maranhão, o mesmo passa a existir oficialmente em 2017, mas, já com uma pesquisa de demanda turística realizada no período do ano novo (2016/17) em São Luís, que buscou identificar o perfil dos visitantes neste evento específico e suas impressões sobre a infraestrutura e serviços turísticos. Os dados foram apresentados ao Secretário Adjunto de Turismo do Maranhão e comunidade acadêmica, o qual destacou a necessidade de novas pesquisas similares para que o estado pudesse ter um panorama do perfil dos visitantes.

A partir de então, o Observatório criou um calendário para o ano de 2017 com vistas a identificar o perfil dos visitantes de São Luís nos períodos de alta e baixa temporada, assim como nos períodos festivos e de feriado como Carnaval, São João e Semana da Pátria, e, também realizou duas pesquisas fora da capital, sendo uma na cidade de Alcântara durante o Festejo do Divino Espírito Santo com o apoio do Instituto Federal do Maranhão (IFMA) e outra na cidade de Carolina (Polo Chapada das Mesas) com o apoio da Secretaria Municipal de Turismo de Carolina. Abaixo seguem as pesquisas desenvolvidas e o número de entrevistados:

1. Pesquisa de Demanda e Satisfação Turística - Ano Novo 2016/17 - 124 questionários;

2. Pesquisa de Demanda e Satisfação Turística - Alta Temporada 2017/1 - 287 questionários; 
3. Pesquisa de Demanda e Satisfação Turística - Carnaval - 80 questionários;

4. Pesquisa de Demanda e Satisfação Turística - Baixa Temporada 2017/1 - 178 questionários;

5. Pesquisa de Demanda e Satisfação Turística - São João - 509 questionários;

6. Pesquisa de Demanda e Satisfação Turística - Alta Temporada 2017/2 - 233 questionários;

7. Pesquisa de Demanda e Satisfação Turística - Semana da Pátria 2017 - 146 questionários;

8. Pesquisa de Demanda e Satisfação Turística - Baixa Temporada 2017/2 - 182 questionários.

Além destas pesquisas de campo, o Observatório realizou o levantamento da taxa de ocupação hoteleira junto a Associação Brasileira da Indústria de Hotéis do Maranhão (ABIHMA) entre os anos de 2010 a 2017, e, no site da Infraero identificaram o fluxo de passageiros (embarque e desembarque) no aeroporto Marechal da Cunha Machado.

Em dezembro de 2017 foi realizado o lançamento oficial do Observatório com suporte e apoio da Secretaria de Estado de Turismo do Maranhão que abraçou a causa, e, desde então financia as pesquisas de campo na capital. O somatório de pesquisadores que participaram das pesquisas em 2017 ultrapassou oitenta pessoas que se disponibilizaram a participar das pesquisas com o objetivo de levantar dados até então inexistentes e/ou ultrapassados (Observatório do Turismo do Maranhão, 2019).

A Secretaria de Estado de Turismo do Maranhão passou a disponibilizar o transporte e alimentação dos pesquisadores para o deslocamento durante as pesquisas de demanda turística nos principais locais de entrada e saída de São Luís. Das mais de quinze reuniões que tiveram antes e depois das pesquisas em 2017, todos os pesquisadores voluntários afirmaram que puderam vivenciar na prática o aprendizado da sala de aula, principalmente da disciplina Pesquisa de Mercado aplicada ao Turismo, e, também que o contato com os visitantes/turistas possibilitou maior entendimento sobre o perfil e impressões dos mesmos sobre São Luís. Destacaram que se sentiram orgulhosos em poder contribuir para a criação de dados estatísticos do turismo no estado do Maranhão, e, que viam como positiva as ações do Observatório, por estar à frente desta lacuna até então existente no Maranhão.

Ratifica-se que pesquisas de cunho científico, técnico e mercadológico, assim como, a elaboração de projetos turísticos que refletem contextos e necessidades atuais e futuras são fundamentais para o sucesso de qualquer política e plano turístico (Mtur, 2018). Além disso, Castells (2000) e Domareski-Ruiz \& Gândara \& Chim-Miki (2015) afirmam que a 
competitividade de um destino turístico está pautada na capacidade de inovar, mediante o processamento do conhecimento existente no território turístico, portanto, as informações levantadas pelo Observatório do Turismo do Maranhão contribuirão para que o estado do Maranhão seja competitivo satisfazendo "de forma mais eficaz e eficiente (eficiência econômica e ambiental) as necessidades dos fluxos turísticos, preservando as próprias qualidades territoriais e contribuindo para melhorar o bem estar da comunidade local" (Domareski-Ruiz \& Gândara \& Chim-Miki, 2015: 765)

Ao longo do ano de 2017, os responsáveis iniciaram um processo de divulgação dos dados estatísticos, com fins a auxiliar o estado na tomada de decisão, e, também, para que o setor privado pudesse ampliar/melhorar a oferta turística do Maranhão, oferecendo produtos e serviços de qualidade, atendendo às reais necessidades da demanda (turistas), produzindo assim, mais oportunidades às comunidades receptoras, e, sem perder de vista a sustentabilidade dos recursos culturais, históricos e naturais. Crouch \& Ritchie (1999) já afirmavam que o turismo é um fenômeno dinâmico e que se deve acompanhar a complexidade do processo de forma permanente, pois, os destinos são constantemente pressionados a se manterem frente ao mercado.

Nesta perspectiva, coloca-se que tanto as políticas públicas de turismo devem ser uma construção contínua e integrada, tendo como suporte a memória do turismo, e, que os gestores devem se apoiar em ferramentas de inteligência turística, por serem "ferramentas de compreensão e análise de território" (Luque Gil \& Zayas Fernández \& Caro Herrero, 2015:8 - tradução nossa).

Como relatado em uma das reuniões, o pesquisador 27 destaca que estados e municípios devem formalizar plataformas interinstitucionais de dados para facilitar a compreensão dos dados existentes em todas as áreas, pois, o destino turístico como destaca Pearce (2014) é holístico e interage com outros setores, dependendo diretamente de diversas informações.

Já o pesquisador 14 relatou sobre o crescimento do turismo no Maranhão, que para ele é necessário e contínuo as pesquisas e estudos que versem sobre demandas e ofertas turísticas, atendendo a evolução da própria atividade, e, tendo ações estratégias para tratar das transformações. Nesta ótica, Blasco \& Cuevas (2013), Luque Gil \& Zayas Fernández \& Caro Herrero (2015) e Segittur (2013) destacam que um observatório deve prover ferramentas acessíveis para todos os stakeholders, através de diagnósticos, avaliação, observação, perspectiva, geração de novos produtos e serviços, valoração de ferramentas, entre outros.

Em consonância a isso, o pesquisador 30 considera que coletar expectativas e anseios dos turistas em relação aos produtos e serviços turísticos ofertados no Maranhão, 
possibilita uma visão mais ampla em relação às necessidades a serem trabalhadas, de forma a potencializar e direcionar ações de planejamento para uma melhor implementação de políticas públicas (Blasco Franch \& Cuevas Contreras, 2013). De Séde-Marceau (2002) destaca que um Observatório de Turismo deve estar alinhado a alguns aspectos como: problemática do destino e sua gestão, identificação de necessidades, bases de dados territoriais e turística, e, execução do projeto. Ou seja, a partir desta concepção, o autor aponta que o destino turístico passa a ter conhecimento e compreensão da atividade turística, assim como suas dimensões e complexidades.

O Maranhão é um estado com uma diversidade de destinos turísticos pertencentes ao Mapa do Turismo Brasileiro, possuindo características próprias e inseridas em contextos por vezes comuns, mas, também diferenciados pela própria diversidade natural, social e cultural, os quais estão agrupados, tendo assim, a necessidade de serem estudados, para então, prepará-los para o turismo (Maranhão, 2012). Entender as especificidades de cada polo turístico e/ou destino turístico do Maranhão é fundamental para que os gestores públicos e privados do estado compreendam a(s) real(is) necessidade(s) tanto do visitante quanto do residente. Pois, sob a ótica da competitividade, Hjalager (2002), Vera et al. (2011) e Salvado Alves (2008) destacam que os destinos turísticos mais competitivos conduzem novos instrumentos de política e gestão, e, que os territórios vivem em constante mudanças face à globalização, e, que os destinos turísticos devem ser capazes de dar resposta aos desafios impostos mediante inovação, tecnologia, organização, gestão, marketing, qualidade, sustentabilidade, parceria público privada, planejamento participativo e gestão compartilhada.

Está concepção alinha-se ao conceito de destino turístico inteligente (DTI) que para Boes \& Buhalis \& Inversini (2015: 394 - tradução nossa) "pode ser percebido como lugares que utilizam as ferramentas tecnológicas disponíveis e técnicas para permitir que a demanda e a oferta co-criem valor, prazer e experiências para o turista, gerando riqueza, lucro e benefícios para as organizações e destino".

Alguns membros do Observatório como os pesquisadores 02,10 e 19 que já atuam no mercado de trabalho (agências de viagem) destacaram que tais informações levantadas e analisadas pelo Observatório contribuem para que eles possam analisar conjuntamente com os colegas de trabalho e gestores, desenvolvendo estratégias que venham melhorar a qualidade do serviço prestado, assim como formatação de novos produtos, ampliando cada vez mais a competitividade e tomando decisões corretas.

No Brasil, existem observatórios do turismo em cidades como Curitiba (PR) e São Paulo (SP) que são coordenados pela Universidade Federal do Paraná e Secretaria de Estado de Turismo de São Paulo com apoio de entidades privadas, que vem contribuindo 
para o fortalecimento da atividade nos devidos destinos (Mtur, 2012). Em nível internacional, a Organização Mundial do Turismo (OMT) criou La Red Internacional de Observatorios de Turismo Sostenible que pretende reunir observatórios de turismo no mundo para acompanhar o impacto econômico, ambiental e sociocultural do turismo nos destinos (Unwto, 2017). É um incentivo e compromisso que a OMT tem com o setor, por meio de medições estatísticas que permitam uma gestão do turismo com base em evidências confiáveis (Unwto, 2017).

Além das pesquisas mencionadas, o Observatório também realizou o levantamento da reputação online dos atrativos turísticos e empreendimentos turísticos mais comentados no TripAdvisor nas cidades de Barreirinhas, Carolina, São Luís e Tutóia. Outra pesquisa nesta categoria foi no Booking com os empreendimentos hoteleiros mais bem avaliados também. A partir destes dados foi possível identificar como os usuários estão analisando quantitativamente os itens pesquisados. Pois, a reputação online no turismo conforme Feger \& Souza Júnior \& Gândara (2016: 145):

[...] é justificada porque no turismo os depoimentos dos usuários sobre suas experiências inseridos na rede tiveram muita aceitação por parte dos consumidores, tornando-se cada vez mais comum a utilização dos sites de troca de informações especializados, blogs ou redes sociais para mensurar estas experiências de usuários de equipamentos turísticos, como meios de hospedagem, restaurantes e também dos atrativos.

No ano de 2018 além das tradicionais pesquisas de Alta e Baixa Temporada, Carnaval e São João, a do TripAdvisor e Booking, foram realizadas novas pesquisas como: pesquisa de demanda turística na cidade de Barreirinhas (Lençóis Maranhenses) e pesquisa de satisfação com os usuários da Rodoviária de São Luís, além do levantamento quinzenal do número de empreendimentos ofertados e disponíveis no Airbnb, a taxa de ocupação nos feriados em empreendimentos hoteleiros nas cidades de Alcântara, Barreirinhas, Carolina, Imperatriz, São Luís e Tutóia e o levantamento do fluxo de visitantes de São Luís entre os anos de 2007 a 2018.

Novos pesquisadores permanentes e voluntários foram incluídos nas atividades do Observatório para que as pesquisas pudessem acontecer. Em adição, ocorreram novas capacitações e treinamentos para os novatos que estavam pela primeira vez iniciando uma pesquisa de campo. Houve também a abertura para campo de estágio obrigatório e o ganho de dois bolsistas que realizam o tratamento dos dados juntamente com os coordenadores. $\mathrm{A}$ divulgação dos resultados é ampliada para além dos grupos do trade turístico no whatsapp, e passa a contar com o apoio de dois jornais de cunho turístico local que também divulgam os resultados (Cazumbá Turismo e Maranhão Turismo), e, o layout dos infográficos ficam mais dinâmicos e objetivos. 
Em 2018, o Observatório alia-se a Secretaria Municipal de Turismo de São Luís, através da Análise Mercadológica, e, passam a trabalhar de forma cooperada nas pesquisas sobre São Luís, e o Serviço Brasileiro de Apoio a Micro e Pequenas Empresas (seccional Maranhão) disponibiliza uma sala equipada para que os pesquisadores possam desenvolver suas atividades.

Com todo este ganho, os membros passam a construir uma rede de relacionamentos com os setores público e privado, abrindo oportunidades para os mesmos, como relata o pesquisador 06: "estando no Sebrae-MA eu estou permanentemente conversando com empresários e participando de algumas atividades que eles organizam, além de poder divulgar os trabalhos do Observatório". Boes \& Buhalis \& Inversini (2015) e Hielkema \& Hongisto (2012) destacam que os cidadãos adquirem conhecimento mediante processos, contatos e relacionamentos de forma simultânea, impulsionando a competitividade do cluster turístico, o que resulta em ideias inovadoras, atraindo novas empresas para o local.

A pesquisadora 04, por exemplo, participou de quase todas as pesquisas do Observatório, e declara que: "estar, e fazer parte do Observatório me aproxima do campo e das pessoas, pois, gosto de saber o que o turista pensa sobre minha cidade, e, além disso, aproveito para repassar algumas informações e receber outras". O preceito de inteligência turística perpassa pelo que a pesquisadora destacou conforme observam Jamal \& Jamrozy (2006), que nas últimas duas décadas as informações tornaram-se mais disponíveis, contribuindo para a integração interdisciplinar, inovação, parcerias, colaboração, a fim de gerenciar com sucesso o destino. Esta base é observada por Cohen (2011) como pilares da inteligência turística, e, que são ativados e suportados através da integração de tecnologia da informação e comunicação na cidade.

Em 2019, o Observatório já realizou cinco pesquisas de demanda turística somente em São Luís: Alta e Baixa temporada, Carnaval, Semana Santa e São João, uma na cidade de Alcântara durante o festejo do Divino Espírito Santo, outras pesquisas nas cidades de Cururupu e Raposa. E iniciou a inventariação da oferta turística do município de Cururupu. Além disso, lançou o site para melhor divulgação e concentração de todas as pesquisas, e, mudou o formato de publicação dos infográficos (Figura 2). E, também organizou um Seminário de Turismo na cidade de Guimarães a convite do Conselho Municipal de Turismo. 


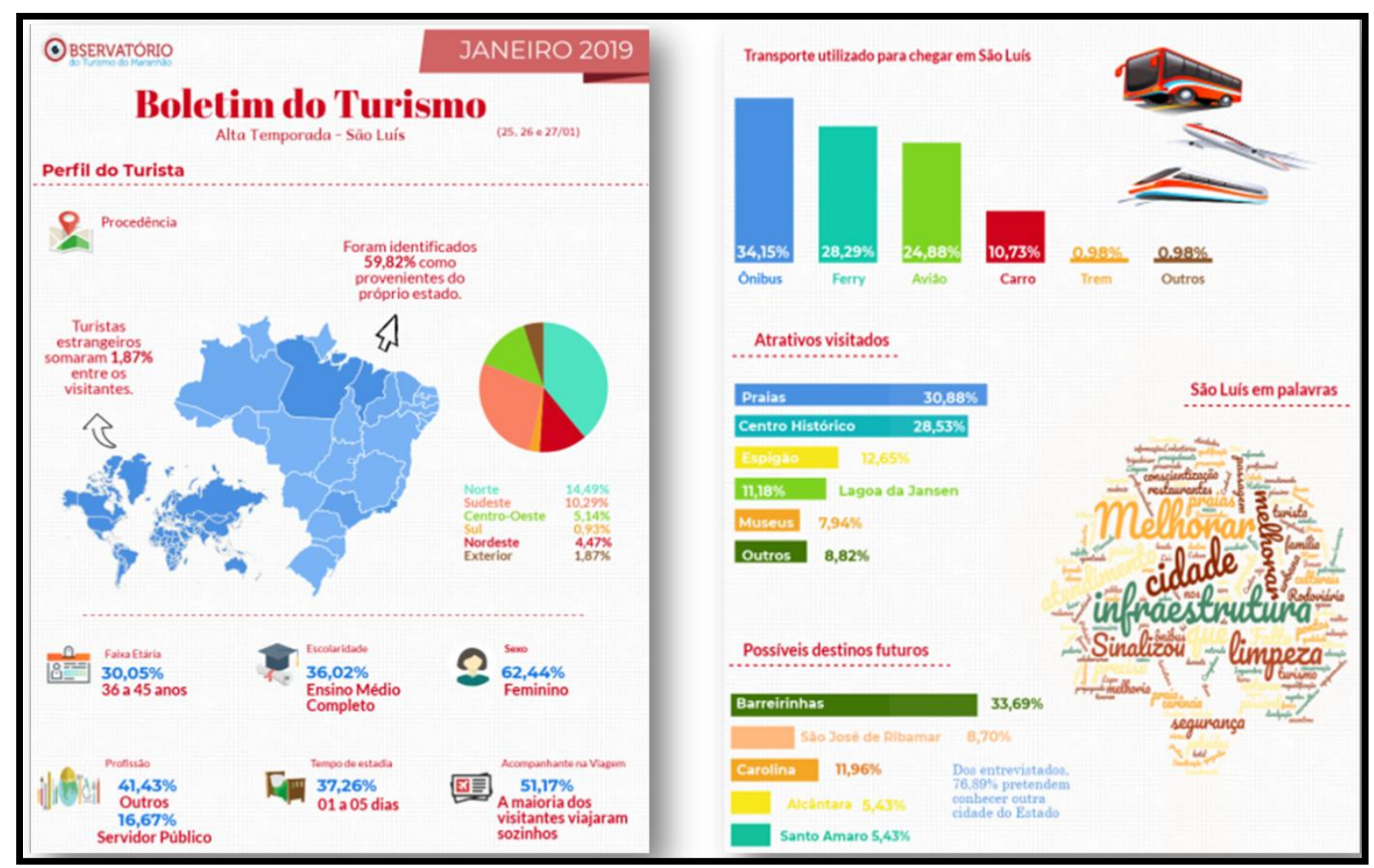

Figura 2: Infográfico alta temporada 2019.1

Fonte: Observatório do Turismo do Maranhão (2019)

A mudança no visual do infográfico do Observatório proporcionou melhor entendimento para o trade, pois, ficou mais colorido, direto, objetivo e claro. Inclusive com vários feedbacks positivos do setor privado, como de um empresário do setor de agências: "adorei o novo visual do infográfico, ficou mais fácil pra entender e analisar com meus funcionários".

Este novo modelo foi desenvolvido pelos dois bolsistas do Observatório que buscaram programas que pudessem dar um melhor visual ao infográfico. Estudaram e aprenderam como manusear, além de vários testes. Como afirmou a bolsista: "trabalhar no Observatório é muito bom, a cada dia me sinto mais desafiada a me superar e aprendo sempre coisas novas". O tripé da Universidade é o ensino, a pesquisa e a extensão, assim como o Observatório, pois, ele reúne este tripé, ensinando, capacitando e pesquisando. O desenvolvimento de instâncias como esta não somente contribui para o fortalecimento do curso de Turismo da UFMA (campus São Luís) como também do campus São Bernardo que já direcionou quatro alunas para estagiar no Observatório, e, que ficaram responsáveis pela pesquisa no TripAdvisor de todos os comentários publicados sobre os atrativos e equipamentos turísticos das cidades de Barreirinhas, Carolina, São Luís e Tutóia, e, levantamento das hastags no Instagram das cidades "concorrentes" de São Luís. 
Atualmente, o Observatório possui uma sala no Complexo Fábrica Santa Amélia no centro histórico de São Luís, onde estão instalados os cursos de Turismo e Hotelaria, no qual também funciona o grupo de pesquisa. Neste espaço, os membros tem a possibilidade de trocar conhecimento sobre todos os projetos, contribuindo e fortalecendo ainda mais o amadurecimento científico do alunado. Portanto, é possível considerar que há muito que se pesquisar sobre o turismo no Maranhão, mas, atualmente, é possível encontrar uma linha do tempo sobre dados específicos do turismo em alguns destinos maranhenses.

\section{Considerações finais}

O crescente aumento do turismo mundial impõe ao Maranhão desafios de consolidar-se cada vez mais, perante outros destinos, e, preparar-se para atender às reais necessidades da demanda turística, inovando e desenvolvendo novos produtos e serviços. A participação e envolvimento de pesquisadores (acadêmicos) têm fortalecido cada vez mais o curso de Turismo da UFMA (campus São Luís) e também a responsabilidade da mesma em investir na qualidade da formação do profissional Turismólogo.

As experiências relatadas apontam que o Observatório é um ganho na formação acadêmica do alunado, pois, com as diversas pesquisas realizadas ele obtém informações que contribuem para o amadurecimento científico, diferenciando-o de outros profissionais e até mesmo Instituições de Ensino Superior.

Pode-se concluir que as experiências relatadas pelos mais diversos membros do Observatório do Turismo do Maranhão condizem com o conceito de destino turístico inteligente, que é justamente criar/construir um destino pautado na inteligência turística, a fim, de torná-lo cada vez mais competitivo. Vê-se necessário a continuação das ações do Observatório do Turismo do Maranhão, assim como, novos relatos como do setor público e privado sobre os ganhos e desafios esperados com o Observatório.

\section{Referências}

Aaker, J. (2007). Dimensions of Brand Personality. Journal of Marketing Research, 34(3), p. 347-357.

Agencia Aysen (2009). Diseño de modelo de observatorio turístico Aysén. Informe final. Guazzini Consultoria.

Blasco Franch, Dani; Cuevas Contreras, Tomá. (2013). Observatorio en Turismo: organismo inteligente para la toma de decisiones en el destino. Revista Iberoamericana de TurismoRITUR, 3 (2), p.25-34.

Boes, Kim; Buhalis, Dimitrious; Inversini, Alessandro. (2015). Conceptualising Smart Tourism Destination Dimensions. In: I. Tussyadiah, A. Inversini (eds.). Information and Communication Technologies in Tourism. Springer International Publishing Switzerland. 
Butler, Richard William. (2008). Tourism: an evolutionary perspective. In: Nelson, James Gordon; Butler, Richard William; Waterloo, Geofray Wall (Orgs.). Tourism and sustainable development: monitoring, planning, managing. Ontario: University of Waterloo.

Castells, M. (2000). A era da informação: economia, sociedade e cultura. In: A Sociedade em rede. São Paulo: Paz e Terra, 1.

Cohen, B. (2011). Smart cities wheel. Recuperado de: < http://www.boydcohen.com/smartcities.html>. Consultado em: 06 abr. 2019.

Crouch, G. I.; Ritchie, J. R. B. (1999). Tourism, Competitiveness, and Societal Prosperity. Journal of Business Research, 44(3), p.137-152.

Domareski-Ruiz, Thays Cristina; Gândara, José Manoel G.; Chim-Miki, Adriana Fumi. (2015). Destinos turísticos como territórios de inovação: análise dos vetores de competitividade urbana à luz dos pressupostos sugeridos pela união europeia, por meio do relatório "state os european cities". Revista Turismo - visão e ação, 17(3), set. - dez.

Framke, W. (2002). The destination as a concept: a discussion of the business-related perspective versus the social - cultural approach in tourism theory. Scandinavian Journal of Hospitality and Tourism, 2 (2), p.92-108.

Gil, Antônio Carlos. (2006). Como elaborar projetos de pesquisa. 4. São Paulo: Atlas.

Hielkema, H., \& Hongisto, P. (2012). No developing the Helsinki smart city: The role of competitions for open data applications. Journal of Knowledge Economy, 4, 190-204.

Hjalager, A. M. (2002). Repairing innovation defectiveness in tourism. Tourism Management, 23(5), p. $465-474$.

Jamal, T.; Jamrozy, U. (2006). Collaborative networks and partnerships for integrated destination management. In: D. Buhalis; C. Costa (eds.). Tourism management dynamics: trends, management, and tools. Amsterdam: Elsevier, pp. 164-172.

Luque Gil, Ana María; Zayas Fernández, Belén; Caro Herrero, José Luis. (2015). Los destinos turísticos inteligentes en el marco de la inteligencia territorial: conflictos y oportunidades. Investigaciones Turísticas, 10, jul./dez., p. 1-25.

Maranhão. (2012). Governo do Estado. Plano Estratégico de Turismo do Estado do Maranhão: Plano Maior 2020 - Relatório final. São Paulo: Chias Marketing.

Marco Lajara, B.; García Lillo, F.; Sabater Sempere, V. (2009). Metodología a seguir para la creación y desarrollo de un Observatorio Turístico de la Provincia de Alicante, III Congreso Internacional de Turismo de Leiria y Oeste (Portugal). Recuperado de: <http://rua.ua.es/dspace/bitstream/10045/16569/1/LEIRIA-COMUNICACION.pdf>. Consultado em: 01 jun. 2019.

Mtur - Ministério do Turismo. (2012). Plano nacional de turismo: o turismo fazendo muito mais pelo Brasil 2013-2016. Brasília, DF.

Mtur - Ministério do Turismo. (2018). Plano nacional de turismo: o turismo fazendo muito mais pelo Brasil 2018-2022. Brasília, DF.

Observatório do Turismo do Maranhão. (2017). Projeto de criação do Observatório do Turismo do Maranhão. São Luís: UFMA.

Observatório do Turismo do Maranhão. (2019). Pesquisas e documentos. Recuperado de: $<w w w . s i t e s . g o o g l e . c o m / v i e w / o b s e r v a t o r i o d o t u r i s m o d o m a r a n h a o>$. Consultado em: 20 jun. 2019.

Pearce, D. (2014). Toward an Integrative Conceptual Framework of Destinations. Journal of Travel Research, 53(2), p.141- 153.

Salvado Alves, A. J. F. (2008). A competitividade dos territórios num contexto de globalização: uma utopia ou uma realidade? Congresso Português de Sociologia.

Santos, S. R. dos. (2016). Revisitando conceitos sobre políticas públicas e gestão do turismo em cidades. Revista de Turismo Contemporâneo. 4(2), jul./dez., p. 286-306. 
Séde-Marceu, M.H. de (2002): Géographie, territories et instrumentation: etat de lieux, reflexions épistémologiques et perspectives de recherche. Mémoire de Habilitation. Université de Franche-Comté, Laboratoire THEMA, Inédito.

Segittur. (2013). Destinos turísticos inteligentes. Recuperado de: $<$ http://www.segittur.es/opencms/export/sites/segitur/.content/galerias/descar gas/documentos/Presentacin-Destinos-Tursticos-Inteligentes.pdf>. Consultado em: 20 mar. 2019.

Todorov, I. (1979). As estruturas narrativas. São Paulo: Perspectiva.

Unwto - World Tourism Organization. (2017). Red de observatorios del turismo sostenible de la OMT. Recuperado de: <http://www.tourism4development2017.org/es/noticias/red-de-observatoriosdel-turismo-sostenible-de-la-omt/>. Consultado em: 02 jun. 2019.

Vera, J.F; López, F.; Marchena, M.J.; Antón, S. (2011). Análisis Territorial del Turismo y Planificación de Destinos Turisticos. Valencia.

Vergara, Sylvia Constant. (2004). Projetos e relatórios de pesquisa em administração. 5. São Paulo: Atlas.

Yin, Robert K. (2001). Estudo de caso: planejamento e métodos. Porto Alegre: Bookman. 